\title{
Thyroid Dysfunction in Hepatitis C Individuals Treated With Interferon-Alpha and Ribavirin - A Review
}

\author{
Luis Jesuíno de Oliveira Andrade ${ }^{1}$, Ajax Mercês Atta ${ }^{2}$, Argemiro D’Almeida Junior ${ }^{3}$ and Raymundo Paraná ${ }^{1}$ \\ ${ }^{1}$ Post-graduate Course in Medicine and Health, Medicine School; ${ }^{2}$ Department of Clinical and Toxicological Aanalysis, Pharmacy \\ School; ${ }^{3}$ Department of Medicine and Health, Medicine School; Federal University of Bahia; Salvador, BA, Brazil
}

\begin{abstract}
Hepatitis C (HCV) is now the main cause of chronic hepatic disease, cirrhosis and hepatocellular carcinoma. Several extrahepatic diseases have been associated with chronic HCV infection, and in most cases appear to be directly related to the viral infection. Thyroid disorders are common in patients with chronic HCV. Some patients with chronic hepatitis $\mathrm{C}$ experience thyroid problems, and thyroid dysfunction may also be a side effect of interferonbased treatment. The principal risk factor for developing thyroid disease in the course of antiviral therapy is the previous positivity for anti-thyroid antibodies (anti-thyroid peroxidase) especially in older women. Screening for autoantibodies and serum thyroid-stimulating hormone is recommended before, during and after interferon-alpha treatment, and patients should be informed of the risk of thyroid dysfunction. This review includes a summary of thyroid disease associated with chronic HCV infection, interferon-alpha and ribavirin for treatment of HCV and potential to induce thyroid dysfunction.
\end{abstract}

Key-Words: Hepatitis C, interferon-alpha, ribavirin, thyroid dysfunction, thyroiditis.

Hepatitis C (HCV) is now the main cause of chronic hepatic disease, cirrhosis and hepatocellular carcinoma. It is estimated that 170 million persons in the world are infected with HCV with a global prevalence of about 3\%. Every year there are estimates of 3 to 4 million new cases of infection due to transfusion contamination, contaminated injection needles, and parenteral exposure [1]. However, the incidence of HCV has either declined or stabilized in recent years [2]. In the United States, HCV remains the most common chronic bloodborn infection [3,4].

Several extrahepatic diseases have been associated with chronic HCV infection and, in most cases, appear to be directly related to the viral infection. These include: hematologic diseases such as cryoglobulinemia and lymphoma, autoimmune disorders such as thyroiditis and the presence of autoantibodies, renal disease, dermatologic conditions such as lichen planus and porphyria cutanea tarda [5-8].

Thyroid disorders are common in patients with chronic HCV, particularly women. Anti-thyroid antibodies are present in $5 \%$ to $17 \%$ of patients with HCV infection, and thyroid disease, primarily hypothyroidism, occurs in $2 \%$ to $13 \%$ of patients and up to $25 \%$ have thyroid antibodies $[9,10]$. The highest prevalence of both thyroid antibodies and thyroid disease is found in older women. Most HCV patients with thyroid dysfunction are middle-aged women with asymptomatic hypothyroidism and do not require specific treatment. However, whether or not the prevalence is higher than in age and sex-matched controls is controversial [11,12].

Some patients with chronic hepatitis C experience thyroid

Received on 27 September 2007; revised 12 April 2008.

Address for correspondence: Dr. Luis Jesuíno de Oliveira Andrade. Rua São Marcelo, 246 - Zildolândia. Zip code: 45.600-700 Itabuna - Bahia - Brazil. Telephone: +55 (73)8812-2755. E-mail: luis_jesuino@yahoo.com.br.

The Brazilian Journal of Infectious Diseases 2008;12(2):144-148. (C) 2008 by The Brazilian Journal of Infectious Diseases and Contexto Publishing. All rights reserved. problems, and thyroid dysfunction may also be a side effect of interferon (IFN)-based treatment. Thyroid autoantibodies and disorders have been reported in patients with chronic hepatitis both before and after IFN-alpha treatment, but the prevalence appears greater in those with chronic HCV virus infection $[13,14]$. Approximately $1 \%$ to $7 \%$ of patients who are treated with chronic IFN-alpha therapy develop painless thyroiditis [14,15]. Other thyroid abnormalities can also occur, including Graves' disease and permanent hypothyroidism, or increased serum anti-thyroid antibody concentrations without thyroid dysfunction, with an estimate relative risk of $4.4 \%$ and an incidence of $5 \%-12 \%$ in HCV patients $[16,17]$. The principal risk factor for developing thyroid disease in the course of antiviral therapy is the previous positivity for antithyroid antibodies (antithyroid peroxidase) especially in older women and family [15]. Patients who develop an IFN induced thyroid disease perhaps are genetically susceptible $[17,18]$.

The presence of low titles of autoantibodies should not be regarded as a contraindication for IFN therapy. Because most patients with increased antibody titles or thyroid dysfunction, especially hypothyroidism, under IFN therapy recover after completing therapy, interruption of IFN therapy may not always be required, although treatment must be interrupted in patients with severe symptoms. Screening for autoantibodies and serum thyroid stimulating hormone (TSH) is recommended before, during and after IFN treatment, and patients should be informed of the risk of thyroid dysfunction [19].

This review includes a summary of thyroid disease associated with chronic HCV infection, IFN and ribavirin (RIBA) for treatment of HCV and potential to induce thyroid dysfunction.

\section{Interferon-alpha}

The IFN are a group of proteins called cytokines produced by white blood cells, fibroblasts, or T cells as part of an immune response to a viral infection or other immune trigger. The name 
of the proteins comes from their ability to interfere with the production of new virus particles [20].

There are three types of IFN: alpha, beta, and gamma. IFNalpha and -beta, which are grouped together as type I interferon, are produced by white blood cells and a type of connective tissue cell called fibroblast. IFN-gamma, or type II IFN, is produced by T cells. Production occurs when the T cells are activated such as during an infection [21].

IFN-alpha and beta share some biological activities, but also have activities that are distinct from each other. These similarities and differences reflect the common and different binding of the IFN to various receptors on the surfaces of human cells [22].

The mechanism by which IFN exerts antitumors or antiviral activity is not clearly understood. However, it is believed that direct antiproliferative action against tumor cells, inhibition of virus replication and modulation of the host immune response play important roles in antitumor and antiviral activities [23].

It has been shown that IFN has antiproliferative and immunomodulatory activities in human cells in vitro that are very similar to those of the mixture of IFN-alpha subtypes produced by human leukocytes. Using IFN in vivo has been shown to inhibit the growth of several human tumors growing in immunocompromised mice [24].

IFN-alpha is totally filtered through the glomeruli and undergoes rapid proteolytic degradation during tubular reabsorption, rendering a negligible reappearance of intact IFN-alpha in the systemic circulation. Liver metabolism and subsequent biliary excretion are considered minor pathways for elimination of IFN-alpha [25].

Conjugation of polyethylene glycol (PEG) to a pharmaceutical protein is a method that increases the lifetime blood circulation of drug. PEG-drug conjugates exhibit enhanced solubility, reduced antigenicity, reduced sensitivity to proteolysis, and reduced rate of kidney clearance. The development of PEG-IFN has significantly improved the eradication rates in patients with chronic hepatitis C. Two forms of PEG-IFN have been developed, based on two pegylation chemistries: the 12-kDa linear PEG-IFN-alpha 2b and the 40-kDa branched PEG-IFNalpha 2a [26].

IFN-alpha is used in a number of conditions, including chronic viral hepatitis, hematological malignancies, renal cell carcinoma and melanoma.

\section{Interrelation of Interferon on Thyroid Function}

Several studies observed that IFN-alpha treatment increased the risk of thyroid dysfunction $[11,27,28]$, whereas in most cases, thyroid dysfunction is reversed after discontinuation of IFN-alpha treatment. It is important to note that IFN-alpha treatment itself is associated with autoimmune manifestations [29]. The development of thyroid dysfunction during IFN-alpha and RIBA combination therapy has been reported to occur in $4.7 \%$ to $27.8 \%$ of patients, with a mean incidence of $12.1 \%$. It is higher than in those treated with IFN alone (6.6\%) [18,30-34].

The clear association between autoimmune thyroid disease and IFN-alpha use suggests that high endogenous IFN-alpha levels may also be associated with naturally occurring autoimmune thyroid disease [35]. The strongest risk factors that were associated with an increased risk of development of thyroid disease during IFN-alpha therapy were female sex and the presence of thyroid autoantibodies, particularly antithyroid peroxidase antibodies, before the initiation of therapy [36].

Thyroid disease is less likely to develop in patients with chronic hepatitis B infection who are treated with IFN-alpha than in those with chronic HCV infection, this finding suggests that HCV and IFN-alpha may have a synergistic role in inducing thyroid disease during antiviral therapy [17]. It is hypothesized that HCV particles will result in an induction of IFN-alpha and -beta production in the thyroid gland as part of the innate immune response [37]. IFN can also activate natural killer cells, maturation and proliferation of dendritic cells, proliferation of memory T cells, and prevention of $\mathrm{T}$ cell apoptosis [38]. These will induce a rise in the thyroid auto-antibodies titer. These antibodies will, in turn, damage the thyroid gland, depending upon genetic predisposition.

The IFN-alpha induced thyroid dysfunction was reversible in $61.2 \%$ of patients, including $55.8 \%$ of patients with hypothyroidism and $69.7 \%$ of those with thyrotoxicosis[34]. The PEG form of IFN seems to have the same effects as standard IFN [39]

\section{Ribavirin}

The RIBA is a nucleoside analogue with a broad spectrum of activity against several RNA and DNA viruses, this drug probably has immunomodulatory effects, and it is possible that RIBA may stimulate the immune system alone or synergistically with IFN-alpha to cause thyroid disease via an autoimmune mechanism [40].

The RIBA is a pro-drug, meaning that it is a chemical precursor for the actual pharmacologically active molecule. The RIBA is activated by cellular kinases which change it into the 5 ' triphosphate nucleotide. In this form it interferes with aspects of RNA metabolism related to viral replication. A number of mechanisms have been proposed for this, but none of these is proven. More than one mechanism may be active [41]. RIBA is readily phosphorylated intracellularly by adenosine kinase to RIBA mono-, di-, and triphosphate metabolites. Ribavirin triphosphate is a potent competitive inhibitor of inosine monophosphate dehydrogenase, viral RNA polymerase and messenger RNA (mRNA) guanylyl transferase (viral). Guanyly ltranserase inhibition stops the capping of mRNA. These diverse effects result in a marked reduction of intracellular guanosine triphosphate pools and inhibition of viral RNA and protein synthesis. RIBA is also incorporated into the viral genome causing lethal mutagenesis and a subsequent decrease in specific viral infectivity. 
The RIBA is an inhibitor of some viral RNA guanylyl transferase and guanine-7N-methyl transferase enzymes, and this may contribute to a defective 5'-cap structure of viral mRNA transcripts and therefore inefficient viral translation for certain DNA viruses, such as vaccinia virus, a complex DNA virus. It has been suggested that incorporation of RIBA into the 5'-end of mRNA transcripts would mimic the 7-methyl guanosine endcap of cellular mRNAs, causing poor cellular translation of these. This would be a cell-toxic effect, but it does not seem to be important at therapeutic RIBA concentrations. Any difference between cellular and viral enzyme handling of RIBA-containing mRNA transcripts is a potential mechanism of differential inhibition of RIBA to translation of mRNAs from viruses [42].

However, RIBA can also enhance the non-virus-induced immune response, suggesting that this drug, as a type 1inducing agent, could trigger autoimmune phenomena in predisposed patients. Indeed, it has been demonstrated that the Th1-like immune response is an important factor for the development and maintenance of organ-specific autoimmune diseases [43,44].

Results of in vitro studies using both human and rat liver microsomal preparations indicated little or no cytochrome P450 enzyme-mediated metabolism of RIBA, with minimal potential for P450 enzyme-based drug interactions. RIBA has two pathways of metabolism: a reversible phosphorylation pathway in nucleated cells; and a degradative pathway involving deribosylation and amide hydrolysis to yield a triazole carboxylic acid metabolite.

\section{Interrelation of Ribavirin on Thyroid Function}

Several studies have reported the development of hypothyroidism and hyperthyroidism in patients treated with IFN monotherapy, being described the incidence of thyroid dysfunction during IFN-alpha and RIBA as well as in combination therapy in men [36]. Therefore, the mean incidence of thyroid dysfunction in patients treated with IFNalpha and RIBA combination therapy (12.1\%) is higher than in those treated with IFN alone (6.6\%) [34].

However, few reports have aimed to investigate the role of RIBA on the occurrence of autoimmune disorders and the data evaluating such therapy and thyroid autoimmune disorders are even more limited [18,45].

The RIBA is a guanosine analogue that plays important immunological effects in vivo, by a differential modulation of Th1- and Th2-like responses, with a specific shift favoring the Th1-like activity [46]. Thus, the RIBA could induce hypothyroidism by Th1-dependent activation of CD8+ T lymphocytes which induce cellular destruction predominantly by the perforin pathway [47].

\section{Thyroid Autoimmunity in Hepatitis C Individuals Treated with IFN-alpha and RIBA}

The principal risk factor for developing thyroid disease in the course of antiviral therapy is the previous positivity for anti-thyroid antibodies especially in older women [15]. Patients who develop an IFN-induced thyroid disease are perhaps genetically susceptible [16]. It has been pointed out that IFNrelated thyroid autoimmune disease may reproduce in its shorttime and long-term outcome the natural history of Hashimoto's thyroiditis [48]. Therefore, it is recommended that the screening for thyroid disease to be routinely performed in all patients with HCV infection who are treated with IFN alone or in combination with RIBA [49].

IFN-alpha treatment for various conditions has been associated with thyroid autoimmunity. The incidence of interferon-induced thyroid autoimmunity has been reported to range from $2.5 \%$ to $42 \%$, possibly depending upon dose and duration of medical therapy and patient characteristics. It is not known whether IFN-alpha initiates autoimmune thyroid disease or simply exacerbates in individuals with subclinical disease [50]. However, it is interesting to observe the thyroid in the first 24 hours of IFN-alpha therapy. The TSH levels tend to decrease while free $\mathrm{T} 4$ and free $\mathrm{T} 3$ remain unchanged. Interleukin 6 (IL-6) levels increase, and tumor necrosis factor and IL-1 levels fall [51]. The main effect of IFN-alpha on the immune system is the enhancement of cell cytotoxicity, very likely sustained by suppression of T helper (Th) 2 and an increase in Th1 immune response [52].

The IFN-alpha therapy induces thyroid autoantibodies in patients with chronic HCV infection and may precipitate thyroid dysfunction in patients with pre-existing autoantibodies [53,54].

The management of IFN-alpha-induced thyroid dysfunction in chronic HCV infection remains a matter of debate. Some patients treated with thyroid medication before IFN-alpha treatment may require increased doses during therapy and decreased doses after IFN-alpha therapy has been completed [55].

The characteristic features of thyroid dysfunction in hepatitis C individuals treated with IFN-alpha and RIBA are generally similar to post-partum or Hashimoto's thyroiditis: autoimmune process, presence of anti-TPO antibodies, variable clinical expression, biphasic presentation in some patients, heterogeneous thyroid parenchyma at ultrasound and negative scintigraphy [56].

Symptoms common in patients with thyroid disease like fatigue, decreased appetite, depression, and myalgias were common in our patients with overt hypothyroidism, whereas nervousness, irritability, fatigue, insomnia, and weight loss were prevalent in those with overt hyperthyroidism. They could easily be mistaken for adverse effects of HCV therapy and thyroid dysfunction could have remained undiagnosed if the patients did not undergo routine periodic screening of TSH levels [18]. These thyroid abnormalities resolve in more than $50 \%$ of patients six months after the discontinuation of IFN treatment [27].

Subacute thyroiditis during combination therapy with IFNalpha and RIBA was observed, but its pathogenesis is still unknown. Four episodes of subacute thyroiditis were described, 
occurring in three patients during antiviral combination therapy. All patients had symptoms compatible with hyperthyroidism, which could be misdiagnosed as IFN side-effects [57]. Silent destructive thyroiditis is seen in up to $5 \%$ of IFN-alpha treated patients. These cases are often characterized by a transient hyperthyroidism followed by a longer hypothyroid phase, which often becomes permanent [58].

The results of the review showed an association between thyroid dysfunction in hepatitis $\mathrm{C}$ individuals and treatment with IFN-alpha and RIBA.

\section{References}

1. Lauer G.M., Walker B.D. Hepatitis C virus infection. N Engl J Med 2001;345:41-52.

2. World Health Organization website. Available at: http:// www.who.int/ csr/disease/hepatitis/whocdscsrlyo2003/en/index3. html. Accessed July 10, 2007.

3. CDC: Recommendations for prevention and control of hepatitis $\mathrm{C}$ virus (HCV) infection and HCV-related disease. MMWR Recomm Rep. 1998;47(RR-19):1-40.

4. Alter M.J., Kruszon-Moran D., Nainan O.V., et al. The prevalence of hepatitis C virus infection in the United States, 1988 through 1994. N Engl J Med 1999;341:556-62.

5. Gumber S.C., Chopra S. Hepatitis C: A multifaceted disease. Review of extrahepatic manifestations. Ann Intern Med 1995;126:615-20.

6. Pawlotsky J.M., Ben Yahia. M, Andre. C, et al. Immunologic disorders in $\mathrm{C}$ virus chronic active hepatitis: A prospective casecontrol study. Hepatology 1994;19:841-8.

7. Cacoub P., Renou C., Rosenthal E., et al. Extrahepatic manifestations associated with hepatitis $C$ virus infection. A prospective multicenter study of 321 patients. The GERMIVIC. Groupe d'Etude et de Recherche en Medecine Interne et Maladies Infectieuses sur le Virus de l'Hepatite C. Medicine (Baltimore) 2000;79:47-56.

8. El-Serag H.B., Hampel H., Yeh C., Rabeneck L. Extrahepatic manifestations of hepatitis $\mathrm{C}$ among United States male veterans. Hepatology 2002;36:1439-45.

9. Huang M.J., Tsai S.L., Huang B.Y., et al. Prevalence and significance of thyroid autoantibodies in patients with chronic hepatitis $\mathrm{C}$ virus infection: a prospective controlled study. Clin Endocrinol (Oxf) 1999;50:503-9.

10. Antonelli A., Ferri C., Pampana A., et al. Thyroid disorders in chronic hepatitis C. Am J Med 2004;117:10-3.

11. Roti E., Minelli R., Giuberti T., et al. Multiple changes in thyroid function in patients with chronic active HCV hepatitis treated with recombinant interferon-alpha. Am J Med 1996;101:482-7.

12. Marazuela M., Garcia-Buey L., Gonzalez-Fernandez B., et al. Thyroid autoimmune disorders in patients with chronic hepatitis $\mathrm{C}$ before and during interferon-alpha therapy. Clin Endocrinol (Oxf) 1996; 44:635-42.

13. Gisslinger H., Gilly B., Woloszczuk W., et al. Thyroid autoimmunity and hypothyroidism during long-term treatment with recombinant interferon-alpha. Clin Exp Immunol 1992;90:363-7.

14. Tong M.J., Reddy K.R., Lee W.M., et al. Treatment of chronic hepatitis $\mathrm{C}$ with consensus interferon: a multicenter, randomized, controlled trial. Consensus Interferon Study Group. Hepatology 1997;26:747-54.

15. Deutsch M., Dourakis S., Manesis E.K., et al. Thyroid abnormalities in chronic viral hepatitis and their relationship to interferon alpha therapy. Hepatology 1997;26:206-10.

16. Prummel M.F., Laurberg P. Interferon-alpha and autoimmune thyroid disease. Thyroid 2003;13:547-51.

17. Fernandez-Soto L., Gonzalez A., Escobar-Jimenez F., et al. Increased risk of autoimmune thyroid disease in hepatitis C vs. hepatitis B before, during and after discontinuing interferon therapy. Arch Intern Med 1998;158:1445-8.
18. Paraná R., Cruz M., Santos-Jesus R., et al. Thyroid disease in HCV carriers undergoing antiviral therapy with interferon plus ribavirin. Braz J Infect Dis 2000;4:284-90.

19. Ramos-Casals M., Trejo O., García-Carrasco M., Font F. Therapeutic management of extrahepatic manifestations in patients with chronic hepatitis $C$ virus infection. Rheumatology 2003;42:818-28.

20. Goeddel D.V., Leung D.W., Dull T.J., et al. The structure of eight distinct doned human leukocyte interferons cDNAs. Nature 1981;290:20-6.

21. Kirchner H. Interferons, a group of multiple lymphokines. Springer Semin Immunopathol. 1984;7:347-74.

22. Brierley M.M., Fish E.N. IFN $\alpha / \beta$ receptor interactions to biologic outcomes: understanding the circuitry [Review]. J. Interferon Cytokine Res 2002;22:835-45.

23. Stark G.R., Kerr I.M., Williams B.R., et al. How cells respond to interferons. Annu Rev Biochem 1998;67:227-64.

24. Picaud S., Bardot B., De Maeyer E., Seif I. Enhanced Tumor Development in Mice Lacking a Functional Type I Interferon Receptor. J. Interferon Cytokine Res 2002;22:457-62.

25. Samuel C.E. Antiviral actions of interferons [Review]. Clin Microbiol Rev 2001;14:778-809.

26. Boulestin A., Kamar N., Sandres-Saune K., et al. Pegylation of IFN- $\alpha$ and Antiviral Activity. J. Interferon Cytokine Res 2006;26:849-53.

27. Preziati D., La Rosa L., Covini G., et al. Autoimmunity and thyroid function in patients with chronic active hepatitis treated with recombinant interferon alpha-2a. Eur $\mathrm{J}$ Endocrinol 1995;132:587-93.

28. Matsuda J., Saitoh N., Gotoh M., et al. High prevalence of antiphospholipid antibodies and anti-thyroglobulin antibody in patients with hepatitis $C$ virus infection treated with interferonalpha. Am J Gastroenterol 1995;90:1138-41.

29. Krause I., Valesini G., Scrivo R., Shoenfeld Y. Autoimmune aspects of cytokine and anticytokine therapies. Am J Med 2003;115:390-7.

30. Sachithanandan S., Clarke G., Crowe J., Fielding J.F. Interferonassociated thyroid dysfunction in anti-D-related chronic hepatitis C. J Interferon Cytokine Res 1997;17:409-11.

31. Dalgard O., Bjoro K., Hellum K., et al. Thyroid dysfunction during treatment of chronic hepatitis $\mathrm{C}$ with interferon alpha: no association with either interferon dosage or efficacy of therapy. J Intern Med 2002;251:400-6.

32. Mazziotti G., Sorvillo F., Stornaiuolo G., et al. Temporal relationship between the appearance of thyroid autoantibodies and development of destructive thyroiditis in patients undergoing treatment with two different type-1 interferons for HCV-related chronic hepatitis: a prospective study. J Endocrinol Invest 2002;25:624-30.

33. Carella C., Mazziotti G., Morisco F., et al. The addition of ribavirin to interferon-alpha therapy in patients with hepatitis $\mathrm{C}$ virusrelated chronic hepatitis does not modify the thyroid autoantibody pattern but increases the risk of developing hypothyroidism. Eur J Endocrinol 2002;146:743-9.

34. Koh L.K., Greenspan F.S., Yeo P.P. Interferon-alpha induced thyroid dysfunction: three clinical presentations and a review of the literature. Thyroid 1997;7:891-6.

35. Prummel M.F., Laurberg P. Interferon- $\alpha$ and Autoimmune Thyroid Disease. Thyroid 2003;13:547-51.

36. Bini E.J., Mehandru S. Incidence of Thyroid Dysfunction During Interferon Alfa-2b and Ribavirin Therapy in Men With Chronic Hepatitis C. A Prospective Cohort Study. Arch Intern Med 2004; $164: 2371-6$.

37. Lloyd A.R., Jagger E., Post J.J., et al. Host and viral factors in the immunopathogenesis of primary hepatitis $\mathrm{C}$ virus infection. Immunol Cell Biol 2007;85:24-32.

38. Tilg H. New insights into the mechanisms of interferon alpha: an immunoregulatory and anti-inflammatory cytokine. Gastroenterology 1997;112:1017-21. 
39. Tran H.A., Attia J., Jones T.L., et al. Pegylated interferon-alpha2-beta in combination with ribavirin does not aggravate thyroid dysfunction in comparison to regular interferon-alpha-2-beta in a hepatitis C population: meta-analysis. J Hepatol Gastroenterol 2007;22:472-6.

40. Snell N.J. Ribavirin - current status of a broad spectrum antiviral agent. Expert Opin Pharmacother 2001;2:1317-24.

41. Smith R.A. \& Kirkpatrick W. (eds.). Ribavirin: structure and antiviral activity relationships, Ribavirin: A Broad Spectrum Antiviral Agent. New York: Academic Press, 1980:1-21.

42. Sidwell R.W., Huffman J.H., Khare G.P., et al. Broad-spectrum antiviral activity of Virazole: 1-§-D-ribofuranosyl-1,2,4triazole-3-carboxamide. Science 1972;177:705-6.

43. Tam R.C., Lim C., Bard J., Pai B. Contact hypersensitivity responses following ribavirin treatment in vivo are influenced by type 1 cytokine polarization, regulation of IL-10 expression, and costimulatory signaling. J Immunol 1999;163:3709-17.

44. Liblau R.L., Singer S.M., McDevitt H.O. Th1 and Th2 CD4+ T cells in the pathogenesis of organ-specific autoimmune disease. Immunol Today. 1995;16:34-8.

45. Sachithanandan S., Clarke G., Crowe J., Fielding J.F. Interferon associated thyroid dysfunction in anti-D-related chronic hepatitis C. J Interferon Cytokine Res 1997;17:409-11.

46. Tam R.C., Pai B., Bard J., et al. Ribavirin polarizes human T cell responses toward a type 1 cytokine profile. J Hepatol 1999;30:376-82.

47. Lowin B., Hahne M., Mattmann C., Tschopp J. Cytolytic T-cell cytotoxicity is mediated through perforin and Fas lytic pathways. Nature 1994;370:650-2.

48. Carella C., Mazziotti G., Morisco F., et al. Long-term outcome of interferon-induced thyroid autoimmunity and prognostic influence of thyroid autoantibody pattern at the end of treatment. J Clin Endocrinol Metab 2001;86:1925-9.
49. Ward D.L., Bing-You R.G. Autoimmune thyroid dysfunction induced by interferon-alfa treatment for chronic hepatitis C: screening and monitoring recommendations. Endocr Pract 2001;7:52-8.

50. Oppenheim Y., Ban Y., Tomer Y. Interferon induced Autoimmune Thyroid Disease (AITD): a model for human autoimmunity. Autoimmun Rev 2004;3:388-93.

51. Corssmit E.P., Heyligenberg R., Endert E., Sauerwein H.P., Romijn J.A. Acute effects of interferon-alpha administration on thyroid hormone metabolism in health men. J Clin Endocrinol Metab 1995;80:3140-4.

52. Vertuani S., Bazzaro M., Gualandi G., et al. Effect of interferontherapy on epitome-specific cytotoxic T lymphocyte responses in hepatitis C virus-infected individuals. Eur J Immunol. 2002;32:144-54.

53. Watanabe U., Hashimoto E., Hisamitsu T., et al. The risk factor for development of thyroid disease during interferon alpha therapy for chronic hepatitis C. Am J Gastroenterol 1994;89:399-403.

54. Marcellin P., Pouteau U., Benhamou J.P. Hepatitis C virus infection, alpha interferon therapy and thyroid dysfunction. J Hepatol 1995;22:364-9.

55. Lisker-Melman M., Di Bisceglie A.M., Usala S.J., et al. Development of thyroid disease during therapy of chronic viral hepatitis with interferon alpha. Gastroenterology 1992;102:2155-60.

56. Moncoucy X., Leymarie F., Delemer B., et al. Risk factors and long-term course of thyroid dysfunction during antiviral treatments in 221 patients with chronic hepatitis C. Gastroenterol Clin Biol 2005;29:339-45.

57. Paraná R., Cruz M., Lyra L., Cruz T. Subacute thyroiditis during treatment with combination therapy (interferon plus ribavirin) for hepatitis C virus. J Viral Hepat 2000;7:393-5.

58. Bohbot N.L., Young J., Orgiazzi J., et al. Interferon-a-induced hyperthyroidism: a three-stage evolution from silent thyroiditis towards Graves’ disease. Eur J Endocrinol 2006;154:367-72. 